Short communication

\title{
Pre-strain rolling as an effective tool for suppression of abnormal grain growth in friction-stir welded 6061 aluminum alloy
}

\author{
I. Vysotskiy, S. Malopheyev, S. Mironov*, R. Kaibyshev \\ Belgorod National Research University, Pobeda 85, Belgorod 308015, Russia
}

\section{A R T I C L E I N F O}

\section{Keywords:}

Aluminum alloys

Plasticity methods

Grains and interfaces

\begin{abstract}
A B S T R A C T
In this work, pre-strain rolling to a small thickness reduction was applied to friction-stir welded 6061 aluminum alloy to suppress abnormal grain growth during post-weld heat treatment. This approach enabled to produce nearly homogeneous microstructure distribution across the weld and thus to avoid strain localization during transverse tensile tests.
\end{abstract}

\section{Introduction}

Friction-stir welding (FSW) is an innovative solid-state joining technology which enables to produce high-quality welds with excellent service properties in various structural materials [1-3]. Due to numerous advantages, FSW has great industrial potential and sometimes even considered as one of the most significant recent achievements in materials joining. However, the essential drawback of this technique is the relatively low stability of the welded material against abnormal grain growth at elevated temperatures [e.g. 4-6]. This phenomenon involves catastrophic growth of few grains which may eventually consume the entire material and thus substantially degrade its mechanical characteristics. The abnormal annealing behavior of friction-stir welded material is often explained in terms of Humphreys's cellular model $[7,8]$, i.e. local imbalance between the pressure for the grain growth and pinning pressure of low-angle boundaries and/or second-phase particles. It should be emphasized, however, that the above model was elaborated for macro-scale homogeneous material whereas the frictionstir welds are characterized by extremely sharp microstructural gradient. The theory of the annealing behavior of such heterogeneous materials has not elaborated yet and therefore the genesis of the abnormal grain growth in friction-stir welds is still not completely clear. Accordingly, there is no clear understanding of how to avoid or inhibit this undesirable effect.

It is worth noting in this regard that $\sim 50$ years ago a simple but effective approach for suppression of abnormal grain growth was proposed [9]. This method involved a pre-strain rolling and was based on the idea of randomization of crystallographic texture which was believed to be responsible for the abnormal grain growth [9]. This old technique appears to be very promising for improvement of thermal stability of friction-stir welds, but, to the best of the authors' knowledge, it has never been applied for this purpose so far. Therefore, the purpose of the current work was evaluation of feasibility of this approach.

\section{Materials and methods}

The program material used in this work was commercial 6061 aluminum alloy in T6 temper condition. This is typical heat-treatable aluminum alloy which is feasible for FSW and exhibits abnormal grain growth during post-weld heat treatment [e.g. 10]. The 3-mm-thickness sheets of the material were friction-stir butt welded by using an AccuStir 1004 FSW machine at a tool rotational speed of $1100 \mathrm{rpm}$ and a welding speed of $760 \mathrm{~mm} / \mathrm{min}$. As shown in the previous work [10], this combination of welding variables results in relatively short FSW thermal cycle and thus minimizes precipitation coarsening in heat-affected zone as well as the concomitant material softening. The welding tool consisted of a shoulder having a diameter of $12.5 \mathrm{~mm}$ and an M5 cylindrical probe of $1.9 \mathrm{~mm}$ in length. To provide full-thickness joining, double-side FSW was applied in mutually opposite directions. The principal directions of the FSW geometry were denoted throughout as the welding direction (WD), transversal direction (TD) and normal direction (ND). The produced joints were subjected to the standard T6 tempering, i.e. solutionized at $540{ }^{\circ} \mathrm{C}(813 \mathrm{~K})$ for $1 \mathrm{~h}$, water quenched and then artificially aged at $160^{\circ} \mathrm{C}(433 \mathrm{~K})$ for $8 \mathrm{~h}$. As found in the previous work [10], such heat treatment results in abnormal grain growth in stir zone. To investigate the effect of the pre-strain rolling on the annealing behavior, the selected welds were cold rolled to either 10 or 20 pct. of thickness reduction along the welding direction prior to the T6 treatment. Microstructural observations were performed by electron

\footnotetext{
* Corresponding author.

E-mail address: S-72@mail.ru (S. Mironov).
} 

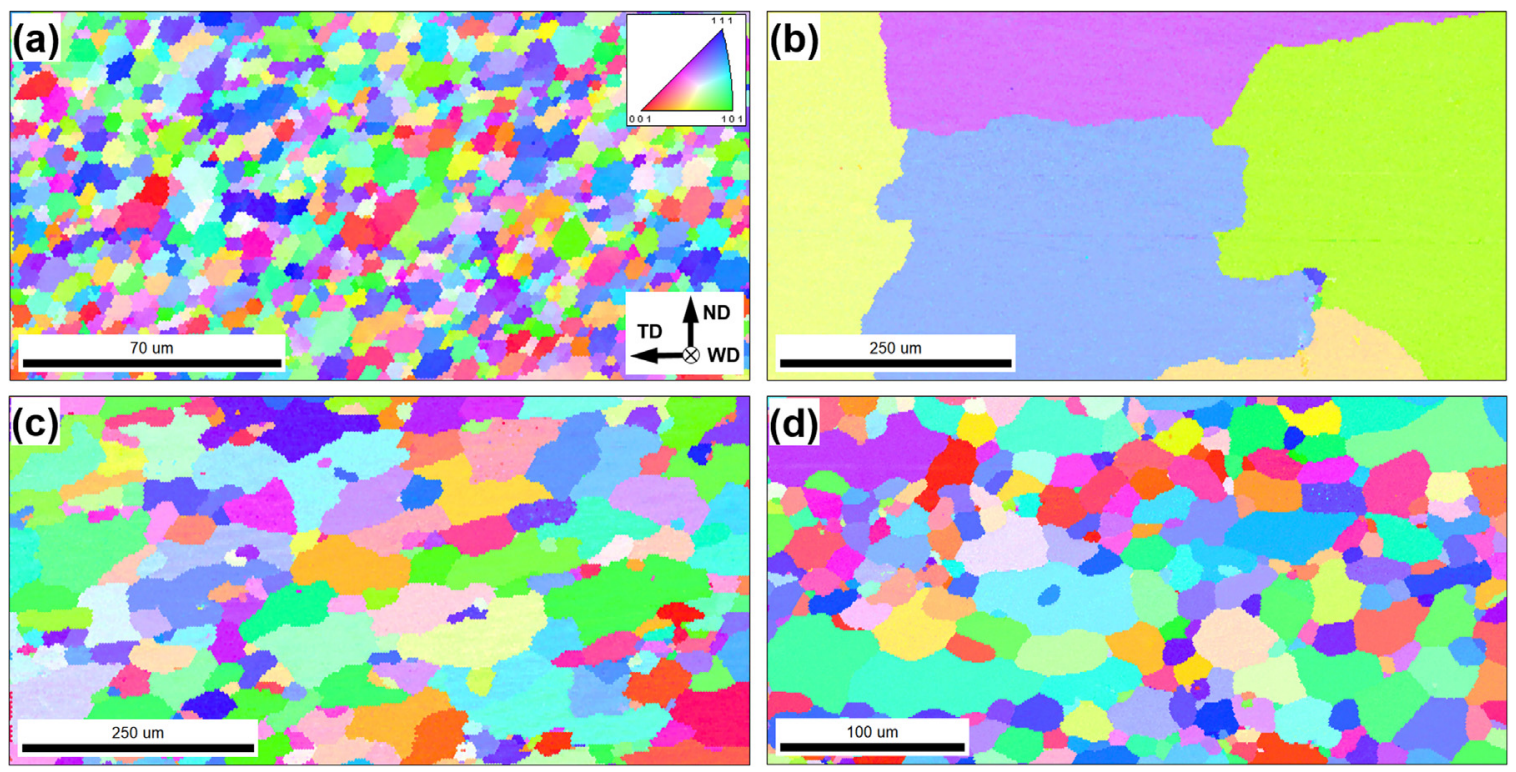

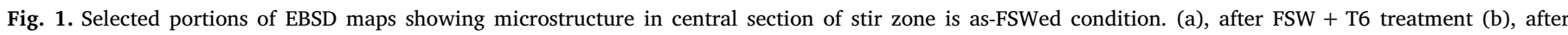
FSW $+10 \%$ CR + T6 treatment (c), and after FSW $+20 \%$ CR + T6 treatment (d). Note difference in scales. Note 2: CR defines cold rolling. See text for details.

backscatter diffraction (EBSD) technique by using a FEI Quanta 600 field-emission-gun scanning electron microscope equipped with TSL OIM $^{\mathrm{TM}}$ software.

To evaluate the effect of the abnormal grain growth on mechanical properties of the welds, transverse tensile tests were conducted. To this end, tensile specimens were machined perpendicular to the welding direction and then pulled to failure by using an Instron 300LX universal testing machine. The specimens were centered at the weld line, had a gauge section of $30 \mathrm{~mm}$ in length and $7 \mathrm{~mm}$ in width, and included all characteristic microstructural zones developed during FSW. The tension tests were performed at ambient temperature and constant cross-head velocity corresponding to an initial strain rate of $10^{-3} \mathrm{~s}^{-1}$. Two tensile specimens were tested for each studied material condition.

\section{Results and discussion}

Typical microstructures evolved in central portion of stir zone after FSW as well as after subsequent post-weld treatments are summarized in Fig. 1. In EBSD maps shown in this figure, individual grains are colored according to their crystallographic axes relative to the welding direction; the color code triangle is given in top right corner of Fig. $1 \mathrm{a}$. Tensile behavior of the selected material conditions is illustrated in Fig. 2.

In the as-welded condition, the microstructure was dominated by reasonably homogeneous equiaxed grain structure (Fig. 1a). The fraction of high-angle boundaries was measured to be $\sim 90$ pct. The constituent second-phase particles of heat-treatable aluminum alloys are well established to dissolve in stir zone [1-3,11-13] and thus they were not studied in this work.

As expected, the subsequent $\mathrm{T} 6$ treatment resulted in the abnormal grain growth (Fig. 1b). It is worth noting that a single-phase material with uniform microstructure and 90 pct. proportion of high-angle boundaries is normally considered to be intrinsically stable against the abnormal grain growth [7]. From a broad perspective, the revealed abnormal grain growth may be associated with partial re-precipitation of the second-phase particles during FSW cooling cycle which may essentially affect the subsequent annealing behavior. At present, however, this idea is totally speculative and warrants experimental verification. As follows from Fig. 2a, the post-weld T6 treatment provided excellent strength characteristics of the weld as compared with those for the base material and joint efficiency for the yield strength was virtually 100 pct. On the other hand, weld ductility was found to essentially degrade. From Fig. 2b, it is clear that the ductility degradation originated from localization of tensile strain in the stir zone presumably due to the abnormal coarse grained structure evolved in this region.

The pre-strain rolling gave rise to substantial grain refinement in the stir zone during subsequent T6 tempering (Fig. 1c \& d). The abnormal grain growth was virtually suppressed and therefore the employed approach appears to be very effective. Moreover, the grain refinement effect became more pronounced with increase of degree of the preliminary strain (compare Fig. 1c \& d). After 10 pct. of the pre-strain rolling, the weld exhibited a reasonably uniform distribution of tensile strain (Fig. 2b) and thus the global ductility was improved (Fig. 2a). However, the further increase of the rolling reduction to 20 pct. resulted in preferential strain concentration in the base material region (Fig. 2b) and the respective reduction of the total elongation until failure (Fig. 2a). This observation was presumably attributable to the enhancement of the grain-refinement in the stir zone and the concomitant hardening effect.

Attempting to provide an additional insight into microstructural processes occurring during the post-weld treatments, the evolution of crystallographic texture was examined. To this end, the obtained EBSD data were arranged as 111 and 110 pole figures and summarized in Fig. 3a-c. For comparative purposes, the ideal simple-shear textures expected for face-centered cubic metals are also shown in Fig. 3d (after Fonda et al. [14]).

In the as-welded condition, the evolved texture could be described in terms of superposition of $\{111\}\langle u \nu w\rangle$ fiber texture and $B / \bar{B}\{112\}<110>$ simple-shear texture component (Fig. 3a). The $B / \bar{B}$ is typically observed in friction-stir welded aluminum alloys [14] thus being a well-expectable result. Remarkably, the measured $B / \bar{B}$ texture somewhat deviated from the ideal position (compare Fig. 3a \& d) presumably due to a very specific orientation of shear surface during FSW [14].

The pre-strain rolling to 10 or 20 pct. of reduction followed by T6 tempering resulted in $\sim 25^{\circ}$ WD rotation of the FSW-induced texture but did not alter it fundamentally (Fig. 3b \& c, respectively). The rotation of deformation texture is often observed during recrystallization [15] or even during abnormal grain growth [16] being usually attributable to increased mobility of $\sim 40^{\circ}<111>$ boundaries in cubic metals [15]. Assuming that the texture rotation revealed in Fig. $3 \mathrm{~b} \& \mathrm{c}$ was produced during grain growth, it may be suggested that the pre-strain rolling 

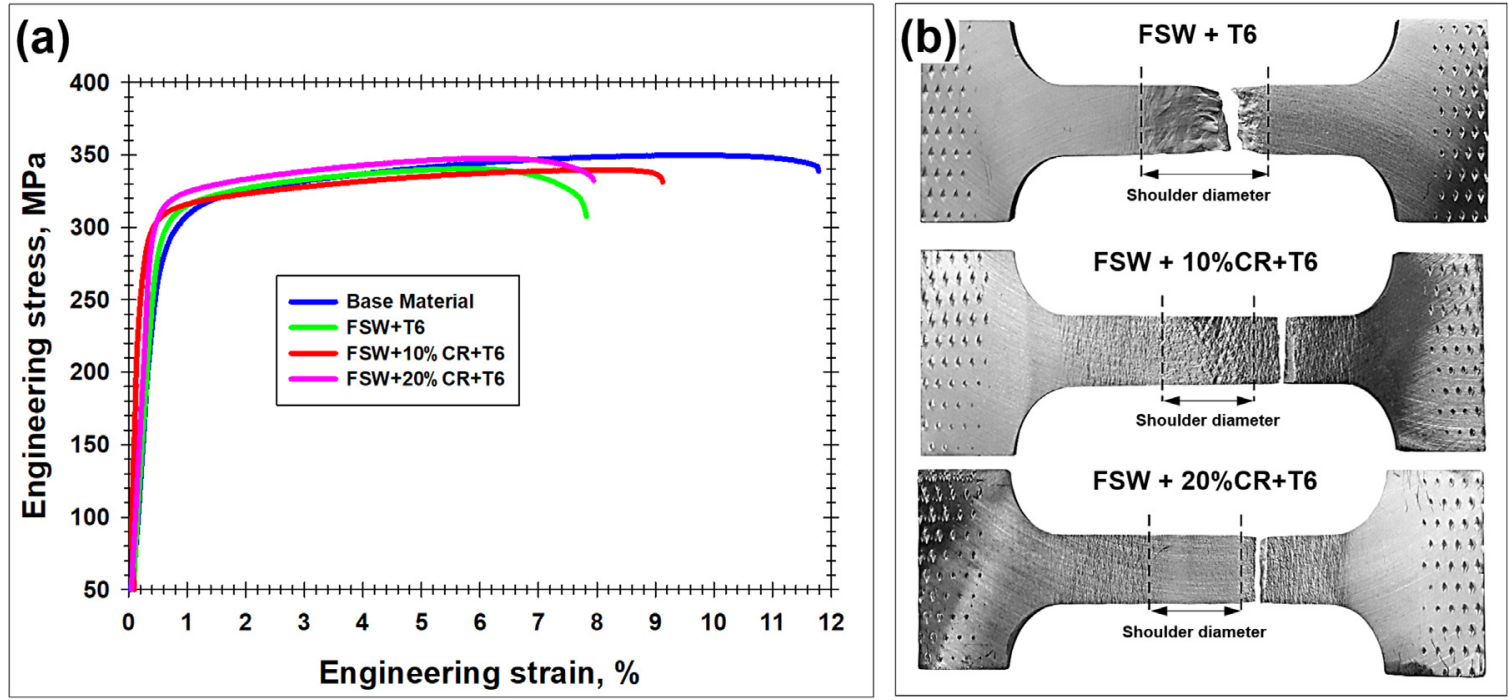

Fig. 2. Deformation diagrams (a) and deformation relief (b) showing effect of pre-strain rolling on mechanical properties of annealed welds. Note: In (b), CR abbreviates cold rolling.

provided no significant change of the FSW-induced texture. Indeed, texture analysis of the pre-strained materials in the rolling reference frame revealed no evidences of rolling texture or recrystallization texture (Supplementary Fig. S1). Given a relatively low degree of the imposed rolling strain (i.e. 10 or 20 pct.), this appears to be a quite expectable result. It is relatively well established now that rolling of aluminum alloys to such low strains primarily results in generation of dislocations which creates only slightly misoriented cells or cell blocks $[17,18]$ but it is not enough for activation of grain subdivision mechanism [19].

It seems therefore that the suppression of the abnormal grain growth observed in the present study did not originate from a breakdown of initial texture, in contrast to the theory developed $\sim 50$ years ago [9]. The pre-strain rolling to such low strains should rather promote
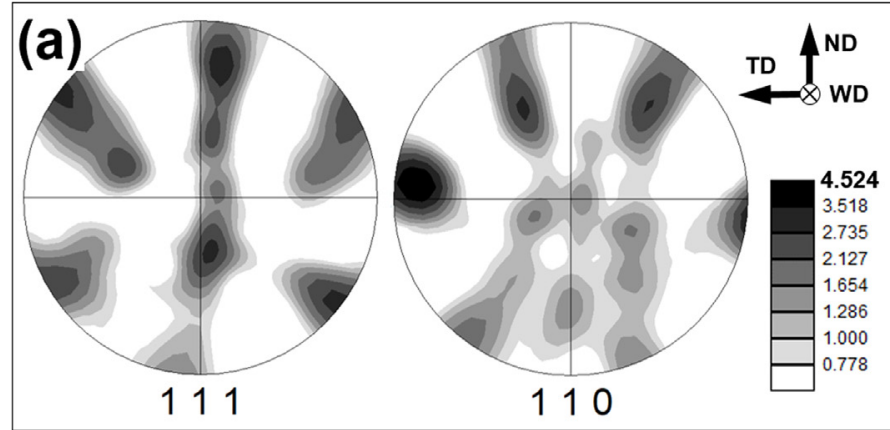

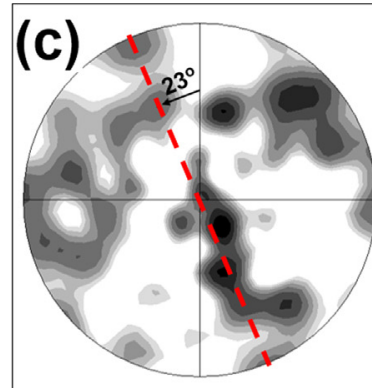

111

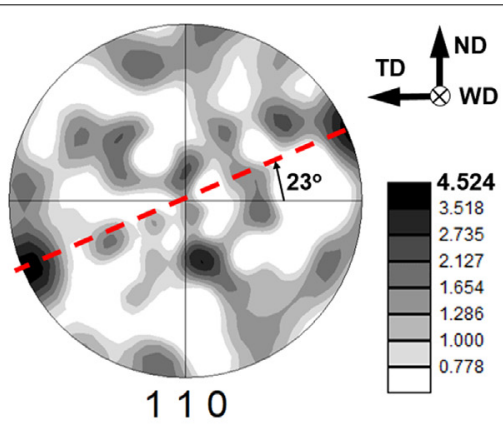

recrystallization during subsequent annealing which perhaps suppresses the abnormal grain growth. However, the mechanism of this presumed effect is not clear and requires further study.

\section{Conclusions}

The pre-strain rolling was shown to be very effective in suppression of abnormal grain growth during annealing of friction-stir welded 6061 aluminum alloy. This effect was suggested to be associated with recrystallization which presumably outpaced the grain growth but the exact mechanism is not clear. The suppression of the abnormal grain growth enabled to avoid strain localization during transverse tensile tests and thus improved weld ductility.

Fig. 3. 111 and 110 pole figures showing texture measured in central section of the stir zone in as-welded condition (a), after FSW $+10 \% \mathrm{CR}+\mathrm{T} 6$ treatment (b), and after FSW $+20 \%$ CR + T6 treatment (c) as well as ideal simple shear textures expected for face-centered cubix metals (after Fonda et al. [14]) (d). In (b) and (c), rotation of original simple-shear texture is shown (see text for details). In (d), SD and SPN abbreviate shear direction and shear plane normal, respectively. Note: CR defines cold rolling. 


\section{Acknowledgements}

Financial support from the Ministry of Education and Science of the Russian Federation (Grant No. 14.584.21.0023, ID number RFMEFI58417X0023) is gratefully acknowledged. The authors also would like to thank the personnel of the Joint Research Centre at Belgorod State University for technical assistance during microstructural observations.Declarations of interest

None.

\section{Data availability}

The raw/processed data required to reproduce these findings cannot be shared at this time as the data also forms part of an ongoing study

\section{Appendix A. Supporting information}

Supplementary data associated with this article can be found in the online version at doi:10.1016/j.msea.2018.07.026.

\section{References}

[1] R.S. Mishra, Z.Y. Ma, Friction stir welding and processing, Mater. Sci. Eng. R 50 (2005) 1-78, https://doi.org/10.1016/j.mser.2005.07.001.

[2] R. Nandan, T. DebRoy, H.K.D.H. Bhadeshia, Recent advances in friction-stir welding - process, weldment structure and properties, Prog. Mater. Sci. 53 (2008) 980-1023, https://doi.org/10.1016/j.pmatsci.2008.05.001.

[3] P.L. Threadgill, A.J. Leonard, H.R. Shercliff, P.J. Withers, Friction stir welding of aluminium alloys, Int. Mater. Rev. 54 (2009) 49-93, https://doi.org/10.1179/ 174328009 X411136.

[4] I. Charita, R.S. Mishra, Abnormal grain growth in friction stir processed alloys, Scr. Mater. 58 (2008) 367-371, https://doi.org/10.1016/j.scriptamat.2007.09.052.

[5] C. Sharma, D.K. Dwivedi, P. Kumar, Effect of post weld heat treatments on microstructure and mechanical properties of friction stir welded joints of Al-Zn-Mg alloy AA7039, Mater. Des. 43 (2013) 134-143, https://doi.org/10.1016/j.matdes. 2012.06.018.
[6] G. İpekoğlu, S. Erim, G. Çam, Investigation into the influence of post-weld heat treatment on the friction stir welded AA6061 Al-alloy plates with different temper conditions, Metall. Mater. Trans. A 45 (2014) 864-877, https://doi.org/10.1007/ s11661-013-2026-y.

[7] F.J. Humphreys, A unified theory of recovery, recrystallization and grain growth, based on the stability and growth of cellular microstructures - I. The basic model, Acta Mater. 45 (1997) 4231-4240, https://doi.org/10.1016/S1359-6454(97) 00070-0.

[8] F.J. Humphreys, A unified theory of recovery, recrystallization and grain growth,growth, based on the stability and growth of cellular microstructures - II. The effect of second-phase particles, Acta Mater. 45 (1997) 5031-5039, https://doi.org/10. 1016/S1359-6454(97)00173-0.

[9] R.W.K. Honeycomb, The Plastic Deformation of Metals, St. Martin's Press, New York, 1968, p. 477.

[10] S. Malopheyev, I. Vysotskiy, V. Kulitskiy, S. Mironov, R. Kaibyshev, Optimization of processing-microstructure-properties relationship in friction-stir welded 6061-T6 aluminum alloy, Mater. Sci. Eng. A 662 (2016) 136-143, https://doi.org/10.1016/ j.msea.2016.03.063.

[11] Y.S. Sato, H. Kokawa, M. Enomoto, S. Jogan, T. Hashimoto, Precipitation sequence in friction stir weld of 6063 aluminum during aging, Metall. Mater. Trans. A 30 (1999) 3125-3130, https://doi.org/10.1007/s11661-999-0223-5.

[12] H.J. Liu, J.C. Hou, H. Guo, Effect of welding speed on microstructure and mechanical properties of self-reacting friction stir welded 6061-T6 aluminum alloy, Mater. Des. 50 (2013) 872-878, https://doi.org/10.1016/j.matdes.2013.03.105.

[13] E.A. El-Danaf, M.M. El-Rayes, Microstructure and mechanical properties of friction stir welded 6082 AA in as welded and post weld heat treated conditions, Mater. Des. 46 (2013) 561-572, https://doi.org/10.1016/j.matdes.2012.10.047.

[14] R.W. Fonda, K.E. Knipling, Texture development in friction stir welds, Sci. Technol. Weld. Join. 16 (2011) 288-294, https://doi.org/10.1179/1362171811Y. 0000000010.

[15] F.J. Humphreys, M. Hatherly, Recrystallization and Related Phenomena, second ed., Elsevier, Oxford, 2004.

[16] S. Mironov, K. Masaki, Y.S. Sato, H. Kokawa, Texture produced by abnormal grain growth in friction stir-welded aluminum alloy 1050, Metall. Mater. Trans. A 44 (2013) 1153-1157, https://doi.org/10.1007/s11661-012-1596-4.

[17] B. Bay, N. Hansen, D. Kuhlmann-Wilsdorf, Deformation structures in lightly rolled pure aluminium, Mater. Sci. Eng. A113 (1989) 385-397, https://doi.org/10.1016/ 0921-5093(89)90325-0.

[18] N. Hansen, D.J. Jensen, Development of microstructure in FCC metals during cold work, Philos. Trans. R. Soc. Lond. A 357 (1999) 1447-1469, https://doi.org/10. 1098/rsta.1999.0384.

[19] D.A. Hughes, N. Hansen, High angle boundaries formed by grain subdivision mechanisms, Acta Mater. 45 (1997) 3871-3886, https://doi.org/10.1016/S13596454(97)00027-X. 